Article

\title{
Detection of Pre-Diabetic patients in the Dental Setting
}

\author{
Hamda AlMesmar ${ }^{1}$, Nadia Saleh ${ }^{2}$,Shiamaa AlMashhadani ${ }^{2, *}$, Khaled Farghali ${ }^{3}$ \\ 1 Director of Dental Services Department, Dubai Health Authority; hsalmaesmar@dha.gov.ae \\ 2 Assistant Director of Dental Services Department, Dubai Health Authority; nsaleh@dha.gov.ae \\ * Correspondence: ssalmashhadani@dha.gov.ae ; Tel.: (00971551038706)
}

\begin{abstract}
Prediabetes is a serious health condition where blood sugar levels are higher than normal, but not high enough yet to be diagnosed as type 2 diabetes. Prediabetes puts one at an increased risk of developing type 2 diabetes and heart disease

Methodology: A cross-sectional study was carried out on 384 patients aged 20-70 years old, attending the dental clinics to assess the risk for diabetes, using the FINDRISC questionnaire, $\mathrm{HbA1} \mathrm{c}$ blood test and a periodontal examination.

Results: The mean age of participants was $38.90 \pm 10.74$. 32.3\% were categorized as no risk, $46.6 \%$ low risk, while $19 \%$ and $2.1 \%$ moderate and high risk of developing diabetes respectively. Tests for serum $\mathrm{HbA} 1 \mathrm{c}$ Level showed $46.1 \%$ had normal $\mathrm{HbA} 1 \mathrm{c}$ followed by $18.0 \%$ and $3.6 \%$ were pre-diabetic and diabetic respectively. $19.3 \%$ of participants had periodontal pockets measuring more than $4 \mathrm{~mm}$ and $15.9 \%$ measuring more than $6 \mathrm{~mm}$.

Conclusion: The study has proven to be useful in identifying patients at high-risk of developing diabetes. Controlling and managing periodontal disease could be a new aspect to include in the standards for diabetes care. Dental settings could be a successful platform to carry out the screening and risk stratification of pre-diabetic patients.
\end{abstract}

Keywords: oral health; pre-diabetes; diabetic; Findrisk; HbA1c 1; periodontal; screening; oralsystemic

\section{Introduction}

Diabetes in all its forms imposes unacceptably high physical, social and economic burden on the communities and countries at all income levels. Prediabetes is a serious health condition where blood sugar levels are higher than normal, but not high enough yet to be diagnosed as type 2 diabetes. Prediabetes puts one at an increased risk of developing type 2 diabetes, heart disease, and $\underline{\text { stroke }}{ }^{1}$.

The risk factors for prediabetes include ${ }^{1}$ :

- Being overweight

- Being 45 years or older

- Having a parent, brother, or sister with type 2 diabetes 
- Being physically active less than 3 times a week

- Ever having gestational diabetes (diabetes during pregnancy) or giving birth to a baby who weighed more than 9 pounds

- Having polycystic ovary syndrome

- Race and ethnicity (certain races are more prone)

\section{Diabetes in the UAE}

World Health Organization - Diabetes country profiles, 2016 illustrate that Diabetes accounts to $3 \%$ mortality all ages in the $\mathrm{UAE}^{2}$. Figures from the International Diabetes Federation (IDF) reveal that, in 2017, $17.3 \%$ of the UAE population between the ages of 20 and 79 have type 2 diabetes. There are over 1 million people living with diabetes in the UAE, placing the country at 15 th place worldwide for age-adjusted comparative prevalence. Trends also indicate that the prevalence of diabetes in the UAE is rising at a faster rate than both the MENA region and the rest of the world. Rapid economic growth, sedentary lifestyles and unhealthy diets characteristic to the UAE are all risk factors, leading to the number of people with diabetes expecting to double to 2.2 million by $2040^{3}$.

\section{Diabetes in Dubai}

Additionally, Dubai Diabetes Survey conducted by DHA in 2017 reported the total prevalence of Diabetes amongst Emiratis in Dubai is 19 per cent, while the undiagnosed diabetes cases amongst Emiratis accounts to 11 percent and the prevalence rate of prediabetes amongst Emiratis is 18.6 per cent $^{4}$. This alarmingly high percentage undoubtedly represents a worrying indication about the future impact of diabetes as a major threat in Dubai.

\section{Oral health consequences of diabetes}

Of late, there is an ample evidence to explain the two-way relationship between diabetes and periodontal disease. The primary cause of periodontal disease is "plaque" that contains pathogenic bacteria that cause inflammation of the gums, leading to the destruction of toothsupporting periodontal tissues. Physiologically active substances associated with the 
inflammation are released from periodontal pockets and then delivered to all parts of the body, where they increase insulin resistance. Additionally, the hyperglycemic state weakens the immune function which protects the body from bacterial infection, leading to easy development and progression of periodontal disease.

Considering the facts and figures expressed above, there is a dire need to develop an effective screening tool to be able assess the risk for diabetes and direct the efforts towards its prevention across Dubai. Since the natural history for diabetes is well understood and it is detectable in the preclinical stage, it is wise to devise a cost-effective, safe and acceptable screening tool that could be easily and widely used in any environment. Diabetes risk calculation can be performed by several health professionals in different settings, of which a dental office could be an ideal site to carry it out as the former caters to patients of all age groups with varied medical backgrounds. More so, the nature of dental treatments mandates multiple visits for most patients, and dental professionals easily develop a rapport with the patients and thus it is conceived feasible to administer a simple, chair-side screening tool for diabetes in the dental offices setting across Dubai. Consequently, if this tool proves accurate and can detect the affected patients, it will prove very valuable not only to prevent the progression of active diabetes, but also limit its complications.

On a similar line, the CDC also suggests that the dental office may be a useful setting in which to identify individuals with undiagnosed prediabetes or diabetes. However, no study has been conducted so far to estimate the risk for diabetes in the population of Dubai; especially in a dental setting. This is the first study of its kind in Dubai.

\section{Aim of the study:}

Early detection of individuals who are at high risk of developing diabetes and correlating the findings with the clinical periodontal disease status.

\section{Materials and Methods}

A cross-sectional study was carried out in a primary health center of DHA to assess the risk for diabetes, using the FINDRISC questionnaire followed by the HbA1c blood test stipulated 
only for the patients identified to be at risk. However, the periodontal examination was carried out for all the patients regardless of the risk category.

Figure 1 Flowchart depicting the procedure of sample selection and clinical examination

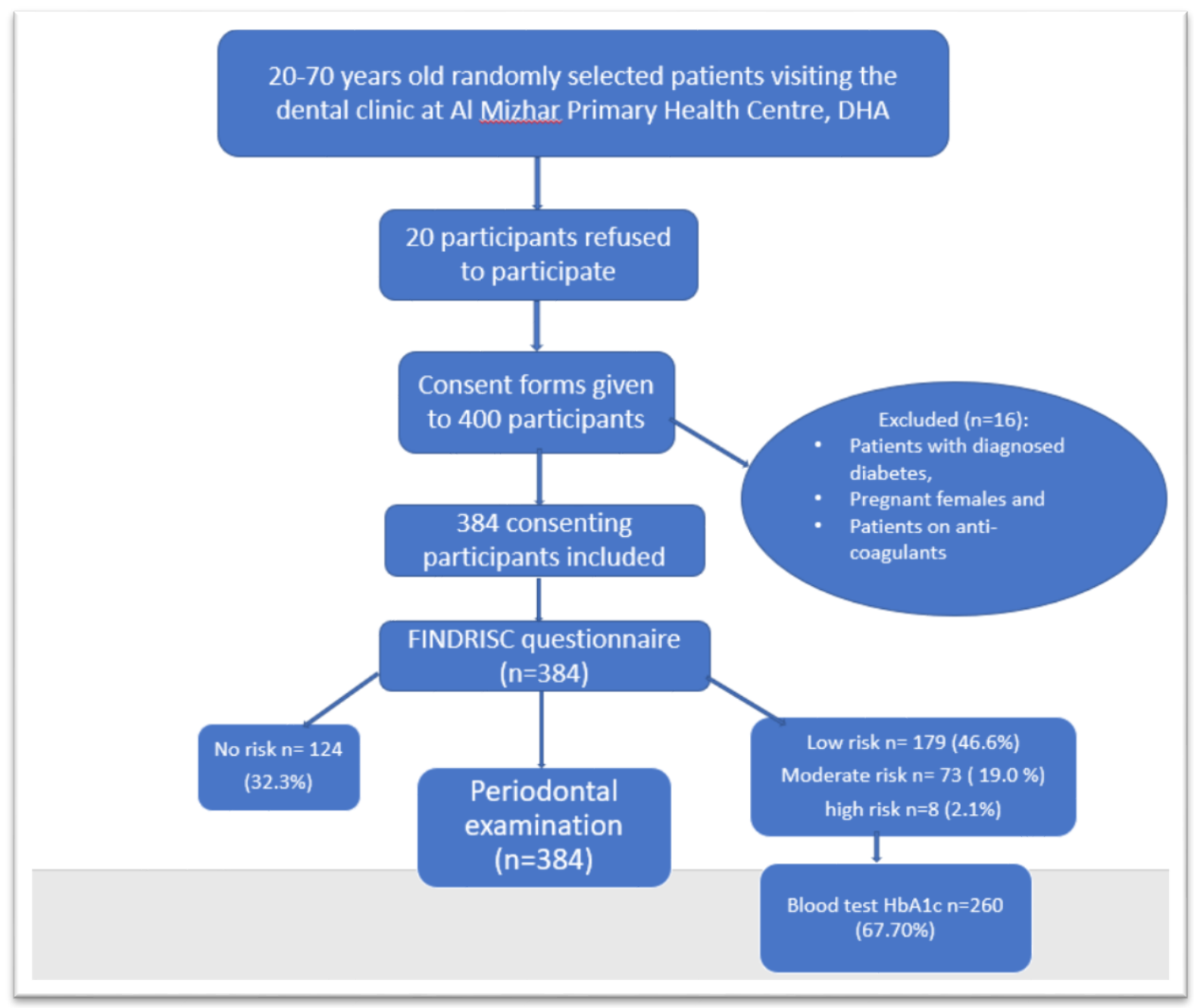

a. Sample design and Subjects:

A simple random sample of the population visiting the dental clinic of Al Mizhar Primary Health Centre was chosen for this study. Both females and males aged 20-70 years were included from the morning and afternoon shifts of dental clinics at the abovementioned health center. Patients sitting in the waiting area of dental clinics were approached and if found interested, a written consent was given to them to be signed and the entire procedure was explained. A total of 20 participants refused to participate, the response rate was $95 \%$. Later, consent forms were given to a total of 400 participants, out of whom 16 were excluded. 


\section{b. Exclusion criteria:}

- patients previously diagnosed with diabetes,

- pregnant females and

- patients taking anti- coagulant medications.

Finally, 384 consenting participants were included in the study. The subjects were screened over a period of 12 months, with 32 patients screened each month; divided over five days a week (around 6 patients per day) in the dental setting of Al Mizhir Primary health center, DHA, Dubai. The screening was accomplished daily based on the availability of the sample with the required criteria.

c. The questionnaire: A screening chart that was simple, practical, non-invasive and inexpensive namely FINDRISC was used. FINDRISC has been successfully implemented as a practical screening instrument to assess diabetes risk and to detect undiagnosed type 2 diabetes in diverse populations.

The Finnish Diabetes Risk Score (FINDRISC) questionnaire is a validated risk assessment tool to predict type 2 diabetes. It estimates the probability of a person to develop diabetes within the next 10 years $^{5}$. It requires no laboratory testing and uses age, BMI, physical activity, vegetable \& fruit intake, medical treatment of hypertension, history of hyperglycemia and family history to determine risk of developing diabetes ${ }^{6}$.

After procuring the consent forms and completing the registration formalities, each patient was given a FINDRISC questionnaire (appendix 1), which takes 2-3 minutes to complete. The questionnaire has eight scored questions, with the total test score providing a measure of the probability of developing type 2 diabetes. The results categorize the participant as high risk, moderate risk, low risk or no risk individual. Resultantly, patients falling in the no risk category received a report on their condition and given printed advice and tips on how to stay healthy. 
Figure 2 CDC recommendations for prediabetes and diabetes identification ${ }^{7}$

\begin{tabular}{|llll|}
\hline Diagnostic test & Normal & Prediabetes & Diabetes \\
\hline $\mathrm{HbA} 1 \mathrm{C}(\%)$ & $<5.7$ & $5.7-6.4$ & $\geq 6.5$ \\
\hline Fasting plasma glucose $(\mathrm{mg} / \mathrm{dL})$ & $<100$ & $100-125$ & $\geq 126$ \\
Oral glucose tolerance test $(\mathrm{mg} / \mathrm{dL})$ & $<140$ & $140-199$ & $\geq 200$ \\
\hline
\end{tabular}

\section{d. HbA1c blood test:}

Next, patients in the high risk, moderate risk or low risk category were requested to take a finger-prick blood sample collected for in-office HbA1c testing with Metrika A1c Now (Bayer Health Care, Sunnyvale, CA), as rapid one-step test. It takes five minutes for the results to appear and the reference HbA1c values were followed as per the CDC guidelines.

\section{e. Periodontal Examination and charting}

Five dentists and five assistants were involved in the examination, who were trained and calibrated before initiating the data collection. All the patients attended their usual appointment and a periodontal charting was done for them after filling out the FINDRISC forms and the blood test. Community Periodontal Index of Treatment Needs (CPITN) was used for the periodontal evaluation. Three indicators of periodontal status are used for this assessment ${ }^{8}$ :

- presence or absence of gingival bleeding

- $\quad$ supra- or subgingival calculus

- periodontal pockets-subdivided into shallow (4-5mrn) and deep (6mm or more).

A specially designed lightweight probe with a $0.5-\mathrm{mm}$ ball tip was used, bearing a black band between 3.5 and $5.5 \mathrm{~mm}$ from the ball tip.

Sextants. The mouth is divided into sextants defined by teeth numbers 18-14, 13-23 24-28, 38-34, 33-43, and 44-48. A sextant should be examined only if there are two or more teeth present and not indicated for extraction. When only one tooth remains in a sextant, it should be included in the adjacent sextant.

f. Statistical Analysis: For the purpose of inter-examiner reliability, the Kappa coefficient (Cohen's Kappa) was used as a measure of agreement between the examiners. $10 \%$ of the 
sample was extracted and measured and a value of 0.6 was recorded which shows good agreement.

The collected data were loaded into Microsoft excel and thereafter proof reading was done. Statistical analysis was carried out using IBM-SPSS version 24. All the categorical variables were expressed as proportion and continuous variables as means and standard deviation. To know the association between socio-demographic factors and FINDRISC score, HbA1C and periodontal health, the Pearson chi square and contingency coefficients were used. Pearson correlation was used to figure out the correlation between FINDRISC score, HbA1c levels and periodontal measurements. Further, to find out the factors influencing the periodontal charting, regression analysis was performed keeping the periodontal scores as the dependent variable. The predicted probabilities were calculated for periodontal scores, later receiver curve was also drawn to know the specificity and sensitivity of the periodontal scores based on the predicted probabilities values. The significance level was fixed at $\mathrm{P}<0.05$ with $95 \%$ confidence interval throughout.

Ethical Approvals: Approval from Ethical Committee for Scientific Research, Dubai Health Authority was obtained (DSREC-04/2018_10).

\section{Results}

\section{Results}

\section{a. Distribution of the Study Participants}

Out of a total of 384 subjects interviewed, majority $71.6 \%$ (275) were female participants and $61.2 \%$ (235) were local population. The mean age of the participants was $38.90 \pm 10.74$ and a large proportion i.e. $52.9 \%$ (203) belonged to 20-40 years, while $44.55 \%$ (171) belonged to 41-60 years age group. In relation to health conditions of the participants, 87.5 $\%$ (336) were healthy individuals. Table 1 and figure 3 
Table 1: Distribution of the study population according to the demographic factors and health condition

\begin{tabular}{|c|c|c|c|}
\hline Factors & Categories & Frequency & Percentage \\
\hline \multirow[t]{2}{*}{ Nationality } & Local & 235 & 61.2 \\
\hline & Non-Local & 149 & 38.8 \\
\hline \multirow[t]{2}{*}{ Gender } & Male & 109 & 28.4 \\
\hline & Female & 275 & 71.6 \\
\hline \multirow[t]{3}{*}{ Age } & 20-40 Years & 203 & 52.9 \\
\hline & 41-60 Years & 171 & 44.5 \\
\hline & 61 and above & 10 & 2.6 \\
\hline \multirow[t]{6}{*}{ Health Condition } & Normal & 336 & 87.5 \\
\hline & Hypertension & 22 & 5.7 \\
\hline & Hyperlypedimia & 7 & 1.8 \\
\hline & Hypothyroidism & 3 & .8 \\
\hline & Hyperthyroidism & 5 & 1.3 \\
\hline & Others & 11 & 2.9 \\
\hline
\end{tabular}


Figure 3 Distribution of the study participants according to the Demographic factors and health condition

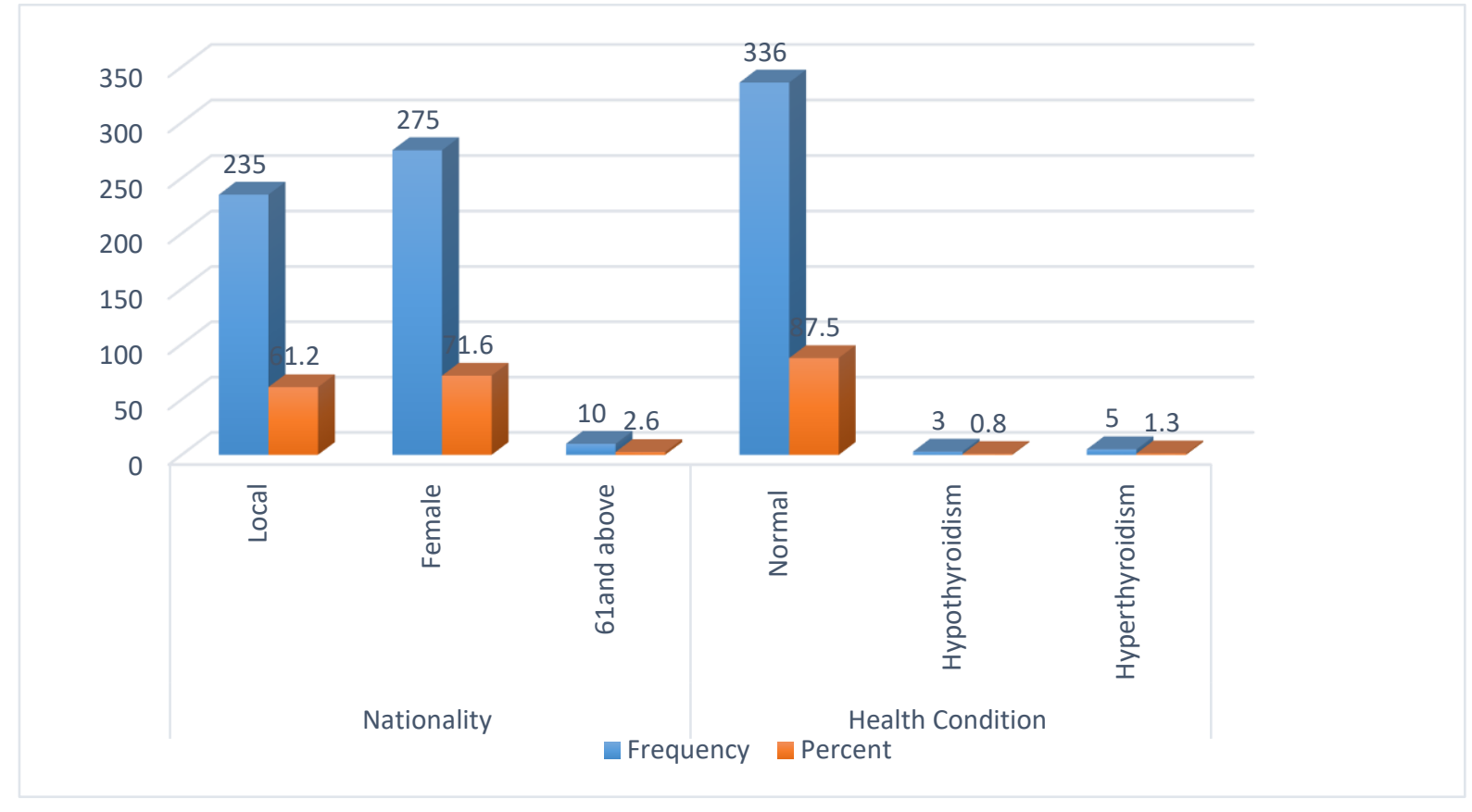

All the 384 participants completed the FINDRISC questionnaire, of which $32.3 \%$ (124) Participants were categorized as having no risk followed by $46.6 \%$ (179) participants were with low risk of developing diabetes, while $19 \%$ (73) and $2.1 \%$ (8) of them were having moderate and high risk of developing diabetes respectively. Further, a total of $32.3 \%$ (124) were exempted from the blood test as they were at a low risk from the FINDRISC questionnaire and the remaining participants were tested for serum HbA1c Level. Accordingly, $46.1 \%$ (177) participants had normal HbA1c followed by $18.0 \%$ (69) and 3.6 $\%$ (14) participants were prediabetic and diabetic respectively. All the participants were subjected to periodontal charting and it was observed that $19.3 \%$ (74) participants had a pocket measuring more than $4 \mathrm{~mm}$ and $15.9 \%$ (61) had periodontal pocket measuring more than $6 \mathrm{~mm}$. Table 2 and figure 4 
Table 2: Distribution of the study population according to the FINDRISC, HbA1C and Periodontal Scores

\begin{tabular}{|c|c|c|c|}
\hline & Categories & Frequency & Percentage \\
\hline \multirow[t]{4}{*}{ FINDRISC } & No Risk & 124 & 32.3 \\
\hline & Low risk & 179 & 46.6 \\
\hline & Moderate risk & 73 & 19.0 \\
\hline & High risk & 8 & 2.1 \\
\hline \multirow[t]{4}{*}{ Hb A1c } & No blood Test & 124 & 32.3 \\
\hline & Normal & 177 & 46.1 \\
\hline & Pre-diabetic & 69 & 18.0 \\
\hline & Diabetic & 14 & 3.6 \\
\hline \multirow{3}{*}{$\begin{array}{l}\text { Periodontal } \\
\text { status }\end{array}$} & Normal & 249 & 64.8 \\
\hline & Attachment loss $>3 \mathrm{~mm}$ & 74 & 19.3 \\
\hline & Attachment loss $>6 \mathrm{~mm}$ & 61 & 15.9 \\
\hline
\end{tabular}

Figure 4: Distribution of the study participants according to FINDRISC, HbA1c and Periodontal Condition

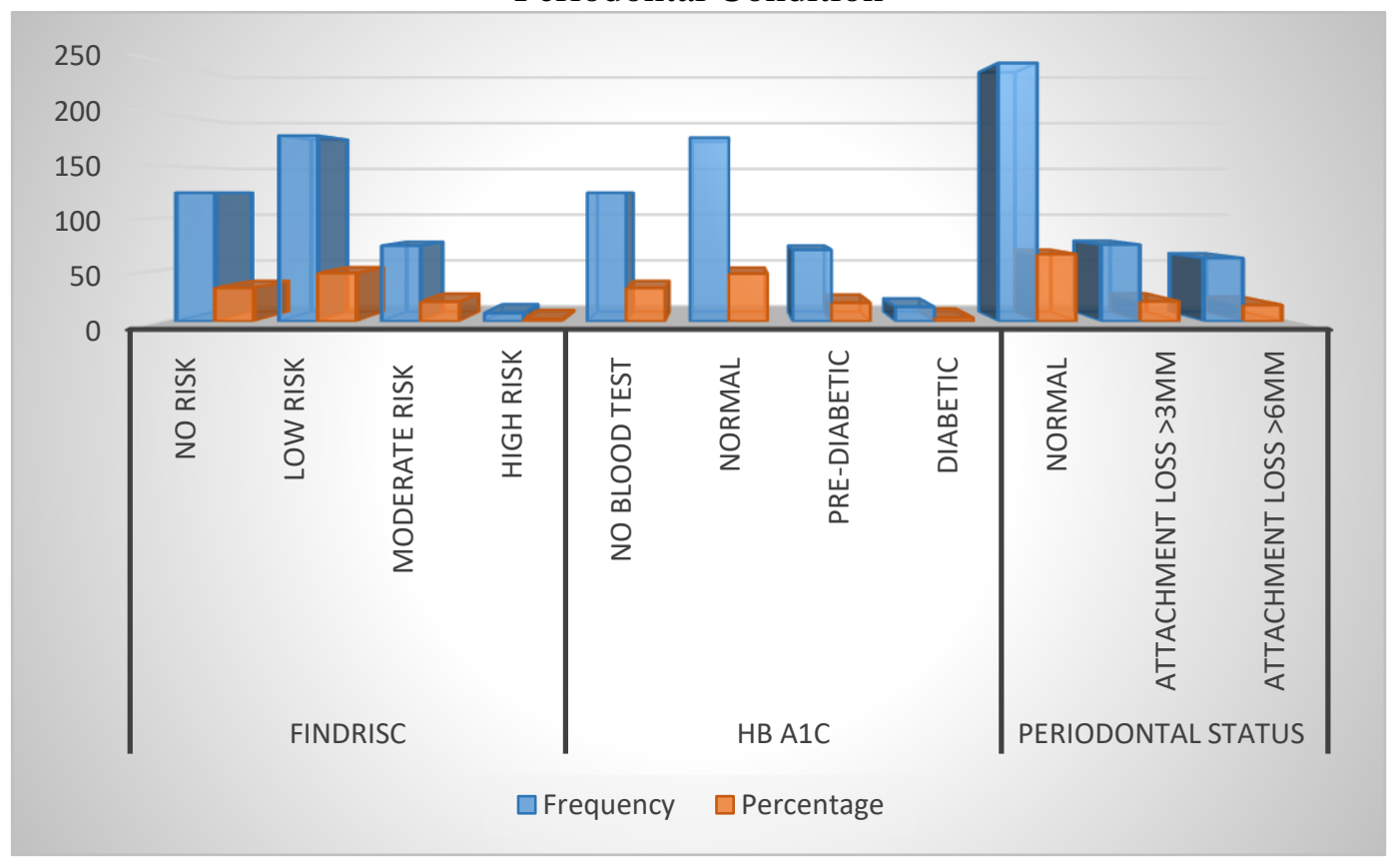

\section{b. Association between demographic factors and FINDRISC score}

With respect to nationality, local participants had greater scores of FINDRISC questionnaire as compared to the non-local participants with $52.3 \%$ (123) vs. $37.6 \%$ for low risk, $19.6 \%$ (46) vs. $18.1 \%$ (27) for moderate risk and $2.6 \%$ (6) vs. $1.35(2)$ high risk scores respectively. 
Also, female participants had a higher FINDRISC score compared to male participants with $20.4 \%$ (56) vs. $15.6 \%$ (17) for moderate risk score, while $2.9 \%$ (8) of the females had a high-risk score whereas no male subjects were found with FINDRISC score of high risk. In terms of age, higher the age of the participant, greater is the FIND RISC score with $60 \%$ (6), $33.9 \%$ (58) and $4.4 \%$ (9) of the high-risk score for the 20-40 years, 41-60 years and 61 years and above group respectively. The health condition of the participants had no significant association with the risk scores assessed by the FINDRISC questionnaire, however, only 1 subject with hypothyroidism $(19.6 \%)$ and 3 subjects $(27.3 \%)$ with other health conditions showed a moderate risk for diabetes. Table 3 and figure 5

Table 3: Association between the Demographic Factors and FINDRISC Score

\begin{tabular}{|c|c|c|c|c|c|c|c|c|c|}
\hline & \multicolumn{8}{|c|}{ FINDRISC Score } & \multirow{3}{*}{ P Value } \\
\hline & \multicolumn{2}{|c|}{ No Risk } & \multicolumn{2}{|c|}{ Low Risk } & \multicolumn{2}{|c|}{ Moderate Risk } & \multicolumn{2}{|c|}{ High Risk } & \\
\hline & $\mathrm{n}$ & $\%$ & $\mathrm{n}$ & $\%$ & $\mathrm{n}$ & $\%$ & $\mathrm{n}$ & $\%$ & \\
\hline \multicolumn{9}{|l|}{ Nationality } & \multirow[t]{3}{*}{$P=0.008$} \\
\hline Local & 60 & 25.5 & 123 & 52.3 & 46 & 19.6 & 6 & 2.6 & \\
\hline $\begin{array}{l}\text { Non- } \\
\text { Local }\end{array}$ & 64 & 43.0 & 56 & 37.6 & 27 & 18.1 & 2 & 1.3 & \\
\hline \multicolumn{10}{|l|}{ Gender } \\
\hline Male & 40 & 36.7 & 52 & 47.7 & 17 & 15.6 & 0 & 0.0 & \multirow[t]{2}{*}{$P=0.054$} \\
\hline Female & 84 & 30.5 & 127 & 46.2 & 56 & 20.4 & 8 & 2.9 & \\
\hline \multicolumn{10}{|l|}{ Age } \\
\hline 20-40 Years & 82 & 40.4 & 112 & 55.2 & 9 & 4.4 & 0 & 0 & \multirow[t]{2}{*}{$\mathbf{P}=\mathbf{0 . 0 0}$} \\
\hline $\begin{array}{r}41- \\
60 Y e a r s \\
\end{array}$ & 42 & 24.6 & 63 & 36.8 & 58 & 33.9 & 8 & 4.7 & \\
\hline 61years and above & 0 & 0 & 4 & 40.0 & 6 & 60.0 & 8 & 2.1 & \multirow[t]{8}{*}{$P=0.796$} \\
\hline \multicolumn{9}{|l|}{ Health condition } & \\
\hline Normal & 109 & 32.4 & 153 & 45.5 & 66 & 19.6 & 8 & 2.4 & \\
\hline Hypertension & 9 & 40.9 & 10 & 45.5 & 3 & 13.6 & 0 & 0 & \\
\hline Hyperlipedemia & 1 & 14.3 & 6 & 85.7 & 0 & 0 & 0 & 0 & \\
\hline Hyperthyoroidism & 3 & 100 & 0 & 0 & 0 & 0 & 0 & 0 & \\
\hline Hypothyroidism & 1 & 20.0 & 3 & 60.0 & 1 & 20.0 & 0 & 0 & \\
\hline Others & 1 & 9.1 & 7 & 63.6 & 3 & 27.3 & 0 & 0 & \\
\hline
\end{tabular}

$\mathrm{P}$ value $=$ Pearson chi square and Contingency Coefficient 
Figure 5: Association between demographic factors and FINDRISC scores.

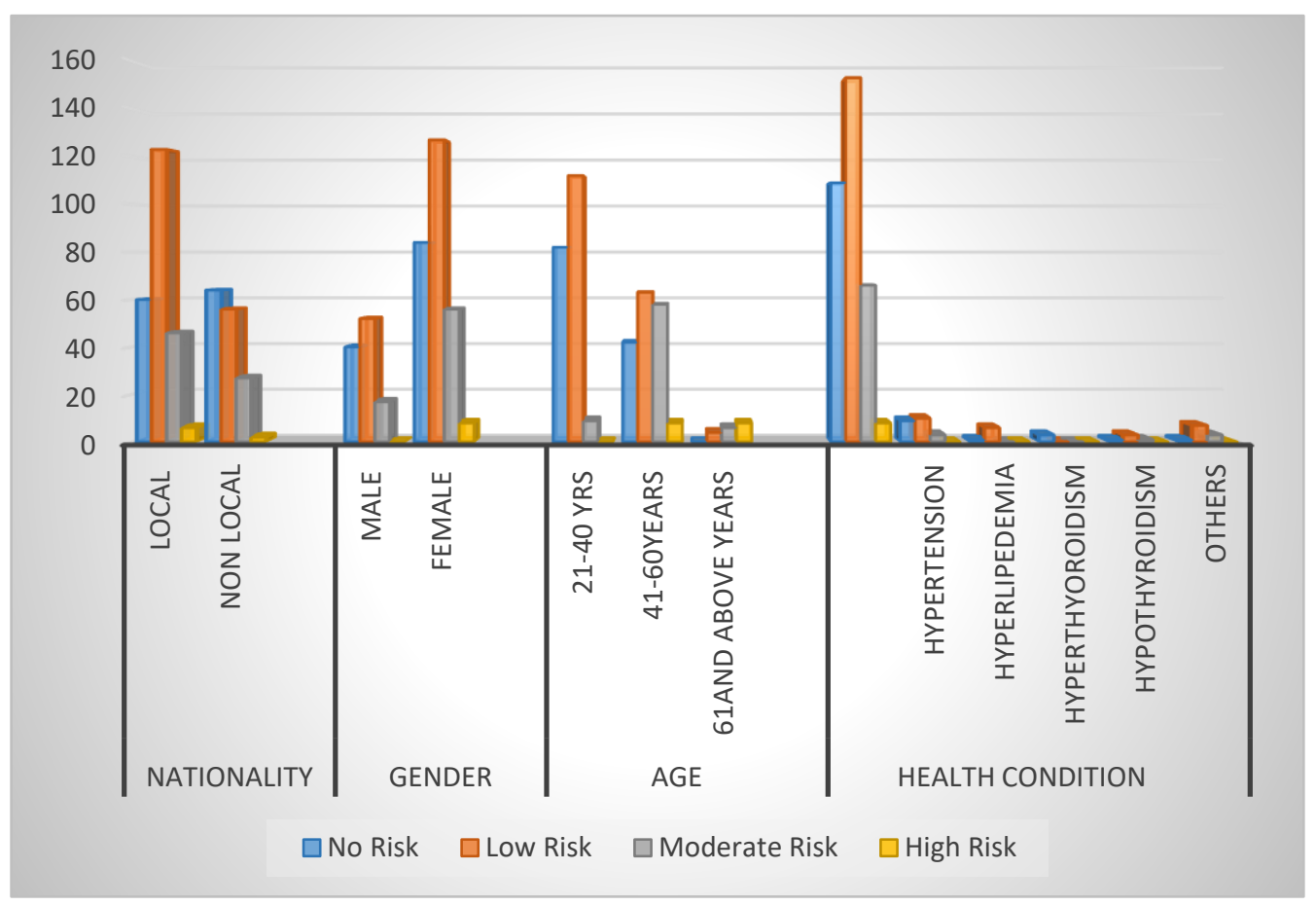

\section{c. Association of demographic factors with serum HbA1c levels}

The association of demographic factors with an HbA1c level showed fashion similar to that of FINDRISC Score. A total of $68.1 \%$ (47) and 85.7\%(12) of the local participants had prediabetic and diabetic levels of HbA1c compared to $31.9 \%$ (22) and $14.3 \%$ (2) of non-local Participants. Next, $60.9 \%$ (42) of the females were in the pre-diabetic stage compared to $39.1 \%$ (27) of the males. Likewise, $57.1 \%$ (8) females and $42.9 \%$ (6) males were diabetic stage of HbA1C levels. With respect to age, 60.9\% (42) belonging to 40-60 years were prediabetic compared to the younger age group which is $34.8 \%$ (24), also $85.7 \%$ (12) participants had diabetes level of HbA1c compared to the younger counterparts $14.3 \%$ (2). The health condition of the participants again posed no significant association with the HbA1c level, however, 2 subjects with hypertension and 2 subjects with hyperlipedemia had prediabetes as measured by HbA1c. Table 4 and figure 6 
Table 4: Association between the Demographic Factors and HbA1c Score

\begin{tabular}{|c|c|c|c|c|c|c|c|c|c|}
\hline & \multicolumn{8}{|c|}{ HbA1c Values } & \multirow{3}{*}{ P Value } \\
\hline & \multicolumn{2}{|c|}{$\begin{array}{c}\text { No Blood } \\
\text { Test }\end{array}$} & \multicolumn{2}{|c|}{ Normal } & \multicolumn{2}{|c|}{ Pre-diabetic } & \multicolumn{2}{|c|}{ Diabetic } & \\
\hline & $\mathrm{n}$ & $\%$ & $\mathrm{n}$ & $\%$ & $\mathrm{n}$ & $\%$ & $\mathrm{n}$ & $\%$ & \\
\hline \multicolumn{9}{|l|}{ Nationality } & \multirow[t]{3}{*}{$P=0.002$} \\
\hline Local & 60 & 48.4 & 116 & 65.5 & 47 & 68.1 & 12 & 85.7 & \\
\hline $\begin{array}{l}\text { Non- } \\
\text { Local } \\
\end{array}$ & 64 & 51.6 & 61 & 34.5 & 22 & 31.9 & 2 & 14.3 & \\
\hline \multicolumn{10}{|l|}{ Gender } \\
\hline Male & 40 & 32.3 & 36 & 20.3 & 27 & 39.1 & 6 & 42.9 & \multirow[t]{2}{*}{$P=0.008$} \\
\hline Female & 84 & 67.7 & 141 & 79.7 & 42 & 60.9 & 8 & 57.1 & \\
\hline \multicolumn{10}{|l|}{ Age } \\
\hline 20-40 Years & 82 & 66.1 & 95 & 53.7 & 24 & 34.8 & 2 & 14.3 & \multirow[t]{3}{*}{$P=0.00$} \\
\hline $\begin{array}{r}41- \\
60 Y e a r s \\
\end{array}$ & 42 & 33.9 & 75 & 42.4 & 42 & 60.9 & 12 & 85.7 & \\
\hline 61and Above Years & 0 & 0 & 7 & 4.0 & 3 & 4.3 & 0 & 0 & \\
\hline \multicolumn{9}{|l|}{ Health condition } & \multirow[t]{7}{*}{$P=0.635$} \\
\hline Normal & 109 & 87.9 & 150 & 84.7 & 64 & 92.8 & 13 & 92.9 & \\
\hline Hypertension & 9 & 7.3 & 10 & 5.6 & 2 & 2.9 & 1 & 7.1 & \\
\hline Hyperlipedemia & 1 & 0.8 & 4 & 2.3 & 2 & 2.9 & 0 & 0 & \\
\hline Hyperthyoroidism & 3 & 2.4 & 0 & 0 & 0 & 0 & 0 & 0 & \\
\hline Hypothyroidism & 1 & 0.8 & 4 & 2.3 & 0 & 0 & 0 & 0 & \\
\hline Others & 1 & 0.8 & 9 & 5.1 & 1 & 1.4 & 0 & 0 & \\
\hline
\end{tabular}

$\mathrm{P}$ value $=$ Pearson chi square and Contingency Coefficient 
Figure 6. Association between demographic factors and HbA1c levels

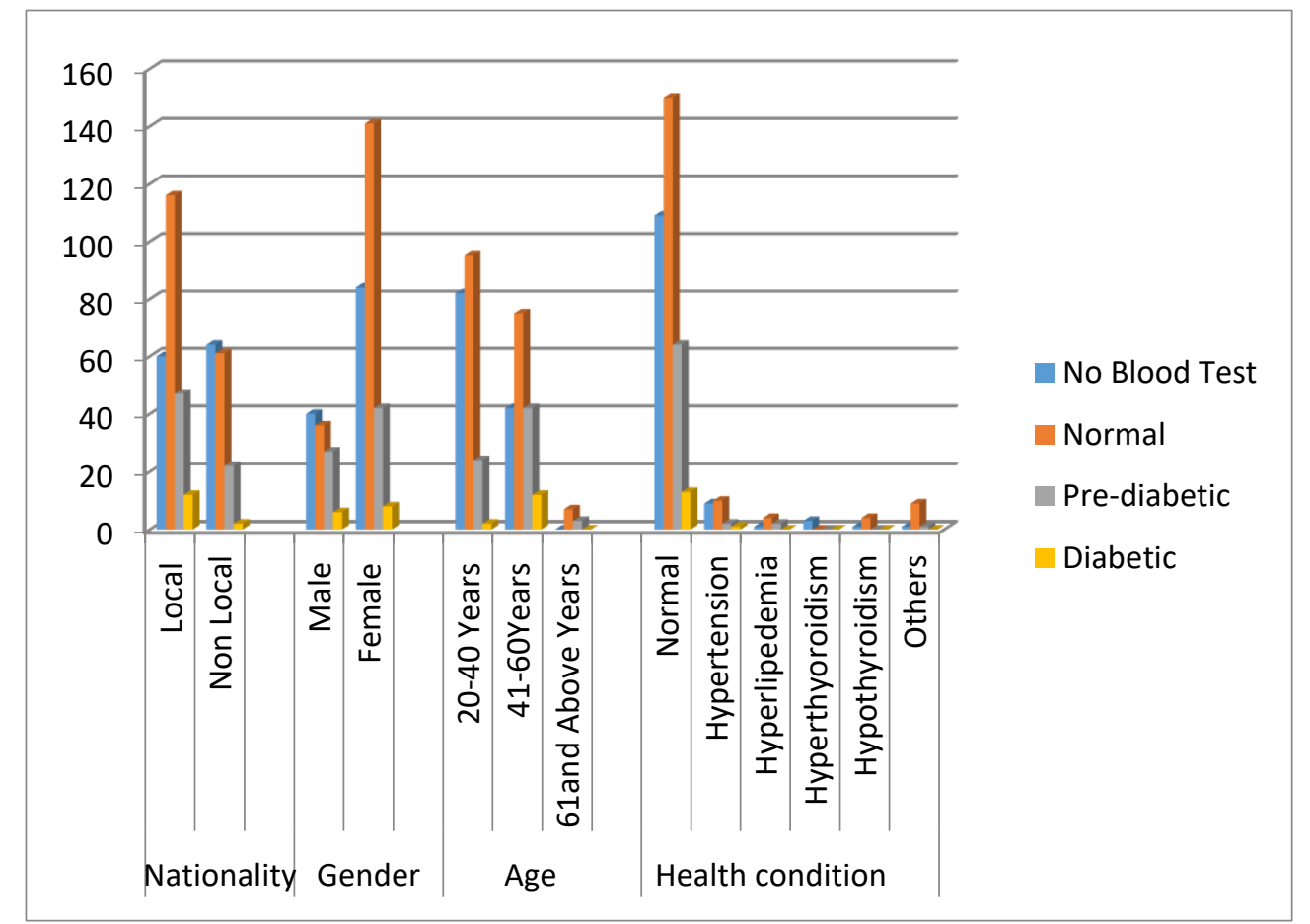

\section{d.Association of Demographic factors and periodontal condition}

Among the subjects having periodontal loss of attachment, $82.2 \%$ (37) were locals presenting with periodontal pockets more than $4 \mathrm{~mm}$ compared to $17.8 \%$ (8) non-locals, similarly $72.5 \%$ (29) locals had a periodontal pocket more than $6 \mathrm{~mm}$ compared to $27.5 \%$ (11) non-locals.

With respect to gender, a greater number of female subjects were observed with periodontal pocket more than $4 \mathrm{~mm} 86.7 \%$ (39) vs $13.3 \%$ (6). Similarly, pockets measuring $4 \mathrm{~mm}$ was found more among the younger adults (20-40)46.7\% (21) vs $42.2 \%$ (19), whereas pockets measuring more than $6 \mathrm{~mm}$ were more among the older adults (41-60), 67.5\% (27) vs $32.5 \%$ (13). Table 5 and figure 7 
Table 5: Association between the demographic factors and Periodontal Condition

\begin{tabular}{|c|c|c|c|c|c|c|c|c|c|}
\hline & \multicolumn{8}{|c|}{ Periodontal score } & \multirow{3}{*}{ P Value } \\
\hline & \multicolumn{2}{|c|}{ Healthy } & \multicolumn{2}{|c|}{$\begin{array}{l}>4 \mathrm{~mm} \\
\text { pocket }\end{array}$} & \multicolumn{2}{|c|}{$>6 \mathrm{~mm}$ pocket } & \multicolumn{2}{|c|}{ Excluded } & \\
\hline & $\mathrm{n}$ & $\%$ & $\mathrm{n}$ & $\%$ & $\mathrm{n}$ & $\%$ & $\mathrm{n}$ & $\%$ & \\
\hline Nationality & & & & & & & & & $P=0.000$ \\
\hline Local & 157 & 56.7 & 37 & 82.2 & 29 & 72.5 & 12 & 54.5 & \\
\hline $\begin{array}{l}\text { Non- } \\
\text { Local }\end{array}$ & 120 & 43.3 & 8 & 17.8 & 11 & 27.5 & 10 & 45.5 & \\
\hline Gender & & & & & & & & & \\
\hline Male & 78 & 28.2 & 6 & 13.3 & 22 & 55.0 & 3 & 13.6 & $P=0.000$ \\
\hline Female & 199 & 71.8 & 39 & 86.7 & 18 & 45.0 & 19 & 86.4 & \\
\hline Age & & & & & & & & & \\
\hline 20-40 Years & 169 & 61.0 & 21 & 46.7 & 13 & 32.5 & 0 & 0 & $P=000$ \\
\hline $\begin{array}{r}41- \\
60 Y e a r s\end{array}$ & 103 & 37.2 & 19 & 42.2 & 27 & 67.5 & 22 & 100 & \\
\hline 61years and above & 5 & 1.8 & 5 & 11.1 & 0 & 0 & 0 & 0 & \\
\hline Health condition & & & & & & & & & $P=0.938$ \\
\hline Normal & 241 & 87.0 & 39 & 86.7 & 36 & 90.0 & 20 & 90.9 & \\
\hline Hypertension & 16 & 5.8 & 2 & 4.4 & 3 & 7.5 & 1 & 4.5 & \\
\hline Hyperlipedemia & 5 & 1.8 & 1 & 2.2 & 1 & 2.5 & 0 & 0 & \\
\hline Hyperthyoroidism & 3 & 1.1 & 0 & 0 & 0 & 0 & 0 & 0 & \\
\hline Hypothyroidism & 3 & 1.1 & 2 & 4.4 & 0 & 0 & 0 & 0 & \\
\hline Others & 9 & 3.2 & 1 & 2.2 & 0 & 0 & 1 & 4.5 & \\
\hline
\end{tabular}

$\mathrm{P}$ value $=$ Pearson chi square and Contingency Coefficient 
Figure 7: Association between demographic factors and periodontal condition

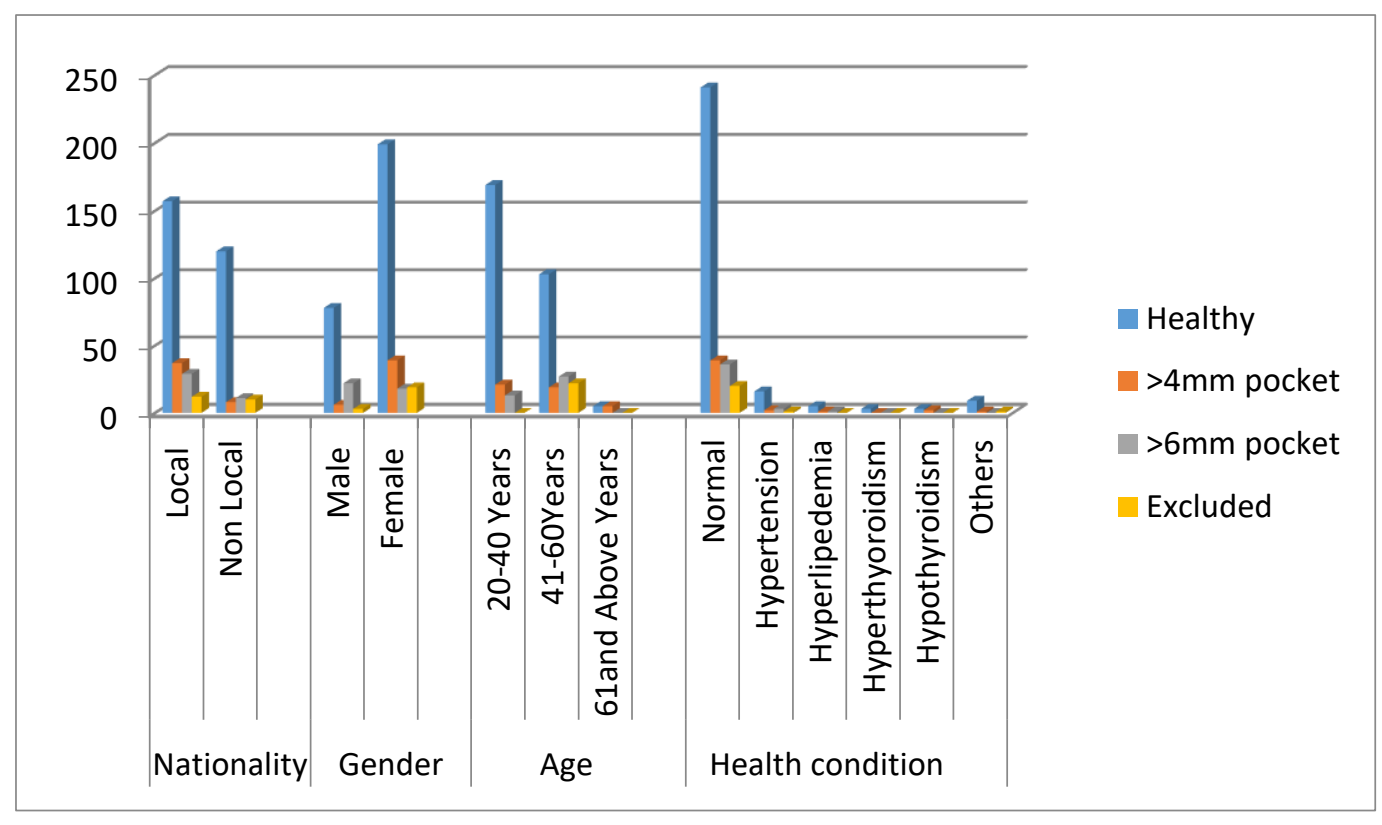

\section{d. Association of FINDRISC score, HbA1c Levels and periodontal conditions}

The presented revealed that a statistically significant association between the periodontal condition and find risk scores as $66.7 \%$ (30) and $75 \%$ (30) subjects belonging to the low risk group had pockets measuring more than $4 \mathrm{~mm}$ and $6 \mathrm{~mm}$ respectively. Next, $11.1 \%$ (5) of the subjects in high risk group had pocket more than $4 \mathrm{~mm}$.

Similarly, $50 \%$ (20) of the subjects belonging to pre-diabetic and $25 \%$ (10) subjects belonging to diabetic stage of HbA1c levels were observed with pockets more than $6 \mathrm{~mm}$. Additionally, 45.8\% (127) of periodontally healthy subjects presented with normal HbA1c levels and $13.7 \%$ (38) of periodontally healthy subjects fall in the pre-diabetic HbA1c category. These observations were statistically significant. Table 6 and figure 8 
Table 6: Association between the FINDRISC score, HbA1c Level and Periodontal condition

\begin{tabular}{|c|c|c|c|c|c|c|c|c|c|}
\hline \multirow{3}{*}{$\mathrm{HbA1c}$} & \multicolumn{9}{|c|}{ Periodontal condition } \\
\hline & \multicolumn{2}{|c|}{ Healthy } & \multicolumn{2}{|c|}{$\begin{array}{c}>4 \mathrm{~mm} \text { of } \\
\text { pocket }\end{array}$} & \multicolumn{2}{|c|}{$\begin{array}{c}>6 \mathrm{~mm} \text { of } \\
\text { pocket }\end{array}$} & \multicolumn{2}{|c|}{ Excluded } & \multirow[t]{2}{*}{ P Value } \\
\hline & $\mathrm{n}$ & $\%$ & $\mathrm{n}$ & $\%$ & $\mathrm{n}$ & $\%$ & $\mathrm{n}$ & $\%$ & \\
\hline $\begin{array}{l}\text { No } \\
\text { investigation }\end{array}$ & 108 & 39.0 & 1 & 2.2 & 0 & 0.0 & 15 & 68.2 & \multirow[t]{4}{*}{$P=0.000$} \\
\hline Normal & 127 & 45.8 & 35 & 77.8 & 10 & 25.0 & 5 & 22.7 & \\
\hline Pre diabetic & 38 & 13.7 & 9 & 20.0 & 20 & 50.0 & 2 & 9.1 & \\
\hline Diabetic & 4 & 1.4 & 0 & 0 & 10 & 25.0 & 0 & 0 & \\
\hline \multicolumn{10}{|l|}{ FINDRISC } \\
\hline No risk & 108 & 39.0 & 1 & 2.2 & 0 & 0 & 15 & 68.2 & \multirow[t]{4}{*}{$\mathbf{P}=\mathbf{0 . 0 0 0}$} \\
\hline Low Risk & 117 & 42.2 & 30 & 66.7 & 30 & 75.0 & 2 & 9.1 & \\
\hline Moderate Risk & 49 & 17.7 & 9 & 20.0 & 10 & 25.0 & 5 & 22.7 & \\
\hline High Risk & 3 & 1.1 & 5 & 11.1 & 0 & 0 & 0 & 0 & \\
\hline
\end{tabular}

$\mathrm{P}$ value $=$ Pearson chi square and Contingency Coefficient 
Figure 8: Association between FINDRISC score, HbA1c level and periodontal condition

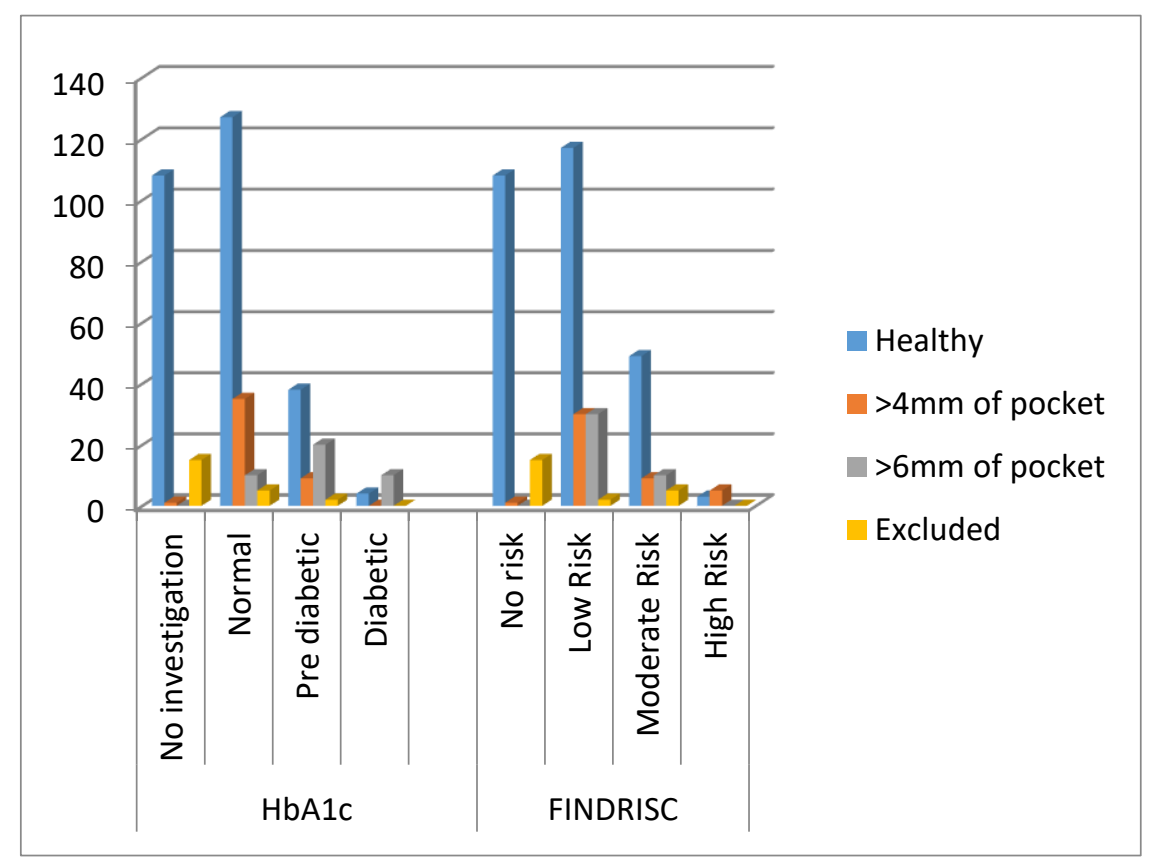

e. Accuracy of periodontal measurement

Using the regression model, the sensitivity and specificity periodontal diagnostic was assessed for the periodontal condition which showed $76.4 \%$ sensitivity and $82.01 \%$ of specificity. In addition, Area Under curve was measured using predictive probabilities of logistic regression for periodontal condition using receiver operating curve that showed a significantly good accuracy of periodontal measurement. (Table 7) 
Table 7: Regression analysis for Periodontal conditions and nationality, age, gender $\mathrm{HbA1C}$ and FINDRISC scores

\begin{tabular}{|c|c|c|c|c|}
\hline \multirow[t]{2}{*}{ Factors } & \multirow{2}{*}{$\begin{array}{l}\text { Odds } \\
\text { Ratio }\end{array}$} & \multicolumn{2}{|c|}{ 95\% C.I. } & \multirow[t]{2}{*}{$P$ value } \\
\hline & & Lower & Upper & \\
\hline Nationality (Local) & 3.058 & 1.457 & 6.421 & .003 \\
\hline Gender (Male) & .896 & .431 & 1.863 & .769 \\
\hline Age $\quad(20-40)$ years & .239 & .052 & 1.095 & .065 \\
\hline years $\quad(41-60)$ & .295 & .066 & 1.310 & .108 \\
\hline HbAlc & .000 & .000 & .005 & .000 \\
\hline HbA1c 5.5 to 6.4 & .735 & .079 & .735 & .000 \\
\hline HbA1c 6.4 and Above & .734 & .079 & .727 & .000 \\
\hline FINDRISC Moderate Risk & .289 & .059 & 1.413 & .125 \\
\hline High Risk & 1.094 & 1.017 & 1.508 & .006 \\
\hline
\end{tabular}

\begin{tabular}{|c|c|c|c|}
\hline & Value & $95 \%$ CI & \\
\hline PCA & $81.5 \%$ & & \\
\hline Pseudo R2 & $27-40 \%$ & & \\
\hline $\begin{array}{c}\text { Sensitivity of Periodontal } \\
\text { charting }\end{array}$ & $76.4 \%$ & $58.83-89.25$ & \\
\hline Specificity Periodontal charting & $82.01 \%$ & $77.42-86.02$ & \\
\hline
\end{tabular}

\section{f. Relationship between FINDRISC, HbA1c and periodontal scores}

Further, a correlation matrix was established using the continuous scores of FINDRISC, HbA1c level and predicted probability of periodontal scores. The correlation matrix showed significant relationship between these three variables. (Table 8). 
Table 8: The Correlation matrix between FINDRISC, HbA1c and Predictive probabilities of periodontal condition.

\begin{tabular}{|l|r|r|r|}
\hline & \multicolumn{2}{|c|}{ Correlations } & \\
\hline & \multicolumn{1}{|c|}{$\begin{array}{c}\text { Periodontal } \\
\text { condition }\end{array}$} & HbA1c & FINDRISC \\
\hline Predicted probability & 1 & $0.760^{* *}$ & $0.536^{*}$ \\
\hline Hb A1c & $.760^{* *}$ & 1 & 0.700 \\
\hline FINDRISC score & $0.536^{*}$ & 0.700 & 1 \\
\hline
\end{tabular}

**. Pearson Correlation is significant at the 0.01 level (2-tailed).

\section{Discussion}

Findings from the present study suggest a potential correlation between FINDRISC, HbA1c level and predicted probability of periodontal scores. Emirati participants and females posed a higher risk for diabetes. Female participants presented with more and deeper periodontal pockets too. All the highrisk participants belonged to a higher age group. It was also discerned that statistically significant association exists in terms of nationality, gender and age with FINDRISC score and the diabetic stage. However, the health condition of the participants in this study was found to have no significant association either with the $\mathrm{HbA1c}$ level or with the periodontal condition.

Almost two-thirds (67.7\%) of the participants in this study were found to have low, moderate or high risk for diabetes and nearly a fifth of the surveyed population posed higher HbA1c levels indicating pre-diabetic or diabetic stages. An alarming proportion i.e. more than a fifth of the study sample (21.6\%) were discovered to be either pre-diabetic or diabetic. Further, of all the pre-diabetic individuals, more than two-thirds (68.1\%) were UAE nationals and likewise even amongst the diabetics, a majority (85.7\%) were UAE nationals again. A potential explanation for this skewed distribution could be that due to the location of the study was a DHA health center where majority of the patients'-cohort is formed by UAE nationals and very few non-nationals, that automatically justifies an overall higher prevalence of these conditions amongst them. 
It is noteworthy that occurrence of diabetes was noticed in $3.6 \%$ of the study participants, which is much lower than the corresponding value outlined in the USA, UK and Australia being 9.4\%[9],6.6 $\%[10]$ and $6 \%[11]$ respectively, as reported by their national statistics. Further, in the present study, $20 \%$ of the participating Emiratis were found to be pre-diabetic, which is slightly higher than reported by Dubai Diabetes Survey conducted by DHA in 2017 (18.6 per cent)[4]. In contrast, the rate of diabetic Emiratis in this study is only $5.1 \%$ which is clearly much lower than the Dubai survey (19 per cent). The prevalence of pre-diabetes in the present study $(18 \%)$ was slightly lower than that reported by S Maples et al[12] (19.2\%) and higher than that reported by NHANES[13] (17.31\%). At the same time the diabetes percentage in the present study ( $3.6 \%$ ) was observed to be higher than reported by S Maples et al[12] (1.2\%) and NHANES[13] (1.64\%). Al Amiri et al[14] reported the prevalence of prediabetes, among overweight and obese Emirati children and adolescents in Sharjah as $5.4 \%$ and $0.87 \%$, respectively, based on OGTT (oral glucose tolerance tests), which are much lower than the present study.

Unlike certain other studies, the present study revealed significant gender differences in the FINDRISC scores as well as $\mathrm{HbA1c}$ values with $\mathrm{P}=0.054$ and $\mathrm{P}=0.008$ respectively; these findings contrast the ones obtained by S Maples et al[12], and W.H. Herman et al[15], where no significant gender differences were noticed in the pre-diabetes and diabetes prevalence. Identical to the findings from the NHANES[13] and S Maples et al[12], age was seen to be significantly associated with the presence of diabetes and pre-diabetes in the present study $(\mathrm{P}=0.00)$.

The findings of this study were consistent with the Wijnand J Teeuw et al [16] where statistically significant association was found between the $\mathrm{HbA1c}$ levels and the periodontal status; and significantly greater number of subjects were spotted with deep pockets (more than $6 \mathrm{~mm}$ ) in the prediabetic and diabetic groups as compared to the subjects with normal HbA1c levels (table and figure 8). The present study also indicates a highly significant association between the periodontal condition and risk for diabetes and the diabetic stage the $\mathrm{p}$ value being $\mathrm{P}=0.000$; which is inconsistent with certain other studies such as Oelisoa Mireille et al[17] who found no significant association between fasting glucose and bleeding on probing.

There has been abundant evidence to support that the presence and severity of periodontal disease is highly associated with the diabetic stage and its complications. Severe periodontitis has been found 
to be associated with poor glycaemic control after a 5-year period and subjects with Clinical Attachment Loss (CAL) of at least $6 \mathrm{~mm}$ had over six times the risk of poor glycaemic control compared to those without it[18]. Additionally, an increase in mean CAL has been associated with an increase in HbA1c. Next, a significant increase in impaired glucose tolerance (IGT) with mean periodontal probing depth (PPD), with each additional millimetre mean PPD corresponding to $0.13 \%$ increase in $\mathrm{HbA1}$ c has been observed after 10-year follow-up[19]. Later, all studies in subjects with types 1 and 2 diabetes found that those with periodontal disease, especially severe disease, and edentulism, had higher risk for diabetes-related complications than participants without or with mild periodontal disease[20]. Lastly, severity of periodontal disease expressed by clinical attachment loss at follow-up was significantly associated with development of diabetes over ten years in a study[19]. However, due to their design and nature, cross-sectional studies are limited to only provide information about associations and are thus not able to an establish a causal relationship.

\section{Conclusions}

The Diabetes Risk Score has proven to be very useful in identifying high-risk subjects and exhibits worrying high proportion of prediabetes and diabetes among Dubai population. Filling in the Diabetes Risk Score may encourage a person who gets a high value to have his/her blood glucose measured and also to improve their lifestyle regardless their glucose levels. Additionally, many individuals with a high Diabetes Risk Score may have unrecognized, asymptomatic diabetes and, therefore, may require blood glucose testing for diagnosis, other clinical assessments, and therapy.

This study emphasizes that periodontal disease adversely affects glucose levels and promotes development of prediabetes and diabetes and vice-versa. The results obtained here would impact the patients and families, health care providers, insurance companies, policy-makers and societies in general, due to the high prevalence of both periodontal disease and diabetes in Dubai afflicting immense physical, mental, social and economic consequences. Controlling and managing periodontal disease could be a new aspect to eventually include in the standards for diabetes care. It undoubtedly requires a shift in paradigm for management and prevention of diabetes and its complications. Dental setting could be successful platform to carry out the screening and risk stratification of diabetic patients, those could further be referred to the relevant medical provider for subsequent treatment and follow up.

Author Contributions: conceptualization, Dr Shiamaa AlMashhadani, Dr Nadia Saleh ; methodology, Dr Shiamaa AlMashhadani; validation, Dr Hamda AlMesmar, Dr Shiamaa AlMashhadani and Dr Nadia Saleh ; writing-original draft preparation, Dr Shiamaa AlMashhadani.; writing-review and editing, Dr Shiamaa AlMashhadani, Dr Hamda ALMesmar and Dr Nadia Saleh; supervision, Dr Hamda AlMesmar ; project administration, Dr Nadia Saleh, Dr Khaled Farghali .; funding acquisition Dr Khaled Farghali ",

Funding: "This research received no external funding"

Acknowledgments: The authors would like to thank Dr Ghayath Aboud, Dr Vijitha Saleem, Dr Sameh Sulaiman and Dr Darwish AlSadik for their valuable input in the data collection process. 
Conflicts of Interest: "The authors declare no conflict of interest."

Appendix 1

Patient questionnaire

Patient Identification number:

Do you have any of the below conditions?

- Diabetic

- $\quad$ Taking drugs affecting your blood (e.g. warfarin, heparin)

- Pregnant

Please answer the following questions:

FINDRISC questionnaire for Diabetes risk assessment

\begin{tabular}{|c|c|c|}
\hline QUESTION & ANSWER & SCORE \\
\hline Age (years) & $\begin{array}{r}<45 \\
45-54 \\
55-64 \\
>64\end{array}$ & $\begin{array}{l}0 \\
2 \\
3 \\
4\end{array}$ \\
\hline Body mass index & $\begin{array}{r}<25 \\
>25-30 \\
>30\end{array}$ & $\begin{array}{l}0 \\
1 \\
3\end{array}$ \\
\hline Waist circumference $(\mathrm{cm})$ & $\begin{array}{r}\text { men }<94, \text { women }<80 \\
\text { men } 94-<102 \text {, women } 80-<88 \\
\text { men }>102 \text {, women }>88\end{array}$ & $\begin{array}{l}0 \\
3 \\
4\end{array}$ \\
\hline $\begin{array}{l}\text { Do you usually have at least } 30 \text { minutes } \\
\text { of physical activity at work and/or during } \\
\text { leisure time (including normal daily activity)? }\end{array}$ & $\begin{array}{l}\text { Yes } \\
\text { No }\end{array}$ & $\begin{array}{l}0 \\
2\end{array}$ \\
\hline $\begin{array}{l}\text { How often do you eat vegetables, fruit or } \\
\text { berries? }\end{array}$ & $\begin{array}{r}\text { Every day } \\
\text { Not every day }\end{array}$ & $\begin{array}{l}0 \\
1\end{array}$ \\
\hline $\begin{array}{l}\text { Have you ever taken medication for high } \\
\text { blood pressure on regular basis? }\end{array}$ & $\begin{array}{l}\text { No } \\
\text { Yes }\end{array}$ & $\begin{array}{l}0 \\
2\end{array}$ \\
\hline $\begin{array}{l}\text { Have you ever been found to have high } \\
\text { blood glucose (e.g. in a health examination, } \\
\text { during an illness, during pregnancy) }\end{array}$ & $\begin{array}{l}\text { No } \\
\text { Yes }\end{array}$ & $\begin{array}{l}0 \\
5\end{array}$ \\
\hline $\begin{array}{l}\text { Have any of the members of your immediate } \\
\text { family or other relatives been diagnosed } \\
\text { with diabetes (type } 1 \text { or type 2)? }\end{array}$ & $\begin{array}{r}\text { No } \\
\text { Yes: grandparent, aunt, } \\
\text { uncle or first cousin } \\
\text { Yes: parent, brother, sister, or own child }\end{array}$ & $\begin{array}{l}0 \\
3 \\
5\end{array}$ \\
\hline & $\begin{array}{r}\text { TOTAL SCORE: } \\
\text { low risk } \\
\text { slightly elevated risk } \\
\text { moderate risk } \\
\text { high risk } \\
\text { very high risk }\end{array}$ & \\
\hline
\end{tabular}

Periodontal screening chart

Right

left

\begin{tabular}{|l|l|l|}
\hline UR6(buccal) & UR1(labial) & UL6(buccal) \\
\hline LR6(buccal) & LR1(lingual) & LL6(buccal) \\
\hline
\end{tabular}


Measurements based on WHO CPI modified (using periodontal probe) $\mathbf{0}=$ absence of condition $1=4-5 \mathrm{~mm}$ $2=6 \mathrm{~mm}$ or more

\section{References}

1. Prediabetes Available from: https://www.cdc.gov/diabetes/basics/prediabetes.html [cited on 10.03.19]

2. United Arab Emirates; Available from: https://www.who.int/diabetes/countryprofiles/are en.pdf [cited on 25.3.19]

3. K.Ogurtsova, J.D.da Rocha, Fernandes, Y.Huang, U.Linnenkamp, L.Guariguata, N.H.Cho and D.Cavan et al. IDF Diabetes Atlas: Global estimates for the prevalence of diabetes for 2015 and 2040 Diabetes Research and Clinical Practice June 2017; 128:405.

4. Dubai

Diabetes

Survey

2017

available

from: https://www.dha.gov.ae/en/DHANews/pages/dhanews1111704558-14-11-2017.aspx [cited on 28.2.19]

5. Godelieve Johanna Maurice vandersmissen1 and Lode Godderis. Evaluation of the Finnish diabetes risk score (FINDRISC) for diabetes screening in occupational health care. International Journal of Occupational Medicine and Environmental Health 2015;28(3):587 - 591 http://dx.doi.org/10.13075/ijomeh.1896.00407

6. Lindström J, Tuomilehto J. The diabetes risk score: a practical tool to predict type 2 diabetes risk. Diabetes Care 2003; 26:725-31.

7. Prediabetes and diabetes identification [Internet] available from: https://www.cdc.gov/diabetes/prevention/pdf/point-of-care-prediabetes-identificationalgorithm_tag508.pdf [cited on 07.03.19]

8. Community Periodontal Index of Treatment Needs (CPITN) available from: https://www.mah.se/CAPP/Methods-and-Indices/for-Measurement-of-dentaldiseases/CPITN/[cited on 17.3.19] 
9. National Diabetes Statistics Report, 2017. Available from: https://www.cdc.gov/diabetes/pdfs/data/statistics/national-diabetes-statistics-report.pdf [cited on 11.3.19]

10. Diabetes UK facts and stats; available from: https://www.diabetes.org.uk/resourcess3/201902/1362B_Facts\%20and\%20stats\%20Update\%20Jan\%202019_LOW\%20RES_EXTE RNAL.pdf [cited on 11.3.19]

11. Australian institute of health and welfare, Diabetes snapshot. Available from: https://www.aihw.gov.au/reports/diabetes/diabetes-snapshot/contents/how-manyaustralians-have-diabetes [cited on 11.3.19]

12. Susan Maples, Saleh Aldasouqi, Randie Little, Heather Baughman, Monica Joshi, Rama Salhi. Detection of Undiagnosed Prediabetes and Diabetes in Dental Patients: A Proposal of a Dental-Office-Friendly Diabetes Screening Tool. Journal of Diabetes Mellitus, 2016, 6, 25-37.

13. C.G. Estrich, M.W.B. Araujo, and R.D. Lipman. Prediabetes and Diabetes Screening in Dental Care Settings: NHANES 2013 to 2016. JDR Clinical \& Translational Research, January 2019; 4 (1): 76- 85.

14. Elham Al Amiri, Mona Abdullatif, Abdishakur Abdulle, Nibal Al Bitar, Elham Zaki Afandi, Monira Parish and Gassan Darwiche. The prevalence, risk factors, and screening measure for prediabetes and diabetes among Emirati overweight/obese children and adolescents. BMC Public Health (2015) 15:1298 DOI 10.1186/s12889-015-2649-6.

15. William H. Herman, GeorgeW. Taylor, Jed J. Jacobson, Ray Burke, Morton B. Brown. Screening for prediabetes and type 2 diabetes in dental offices. Journal of Public Health Dentistry; 75 (2015) 175-182.

16. Teeuw WJ, Kosho MXF, Poland DCW, et al. Periodontitis as a possible early sign of diabetes mellitus. BMJ Open Diabetes Research and Care 2017;5: e000326. doi:10.1136/bmjdrc-2016-000326. 
17. Oelisoa Mireille Andriankaja, Kaumudi Joshipura. Potential association between prediabetic conditions and gingival and/or periodontal inflammation. J Diabetes Invest 2014; 5: 108-114.

18. Borgnakke WS, Ylostalo PV, Taylor GW, Genco RJ. Effect of periodontal disease on diabetes: systematic review of epidemiologic observational evidence. J Clin Periodontol 2013; 40 (Suppl. 14): S135-S152. doi: 10.1111/jcpe.12080.

19. Saito, T., Shimazaki, Y., Kiyohara, Y., Kato, I. Kubo, M., lida, M. \& Koga, T. (2004) The severity of periodontal disease is associated with the development of glucose intolerance in non-diabetics: the Hisayama study. Journal of Dental Research 83, 485-490. doi:10.1177/ 154405910408300610

20. Shultis, W. A., Weil, E. J., Looker, H. C., Curtis, J. M., Shlossman, M., Genco, R. J., Knowler, W. C. \& Nelson, R. G. (2007) Effect of Periodontitis on overt nephropathy and end-stage renal disease in type 2 diabetes. Diabetes Care 30, 306-311. doi:10.2337/dc06-1184.

21. Management of Prediabetes, American association of clinical endocrinologists, available from: http://outpatient.aace.com/prediabetes/management-of-prediabetes [cited on 17.3.19]

22. WHEN IS HEMOGLOBIN A1C INACCURATE IN ASSESSING GLYCEMIC CONTROL? Available from: https://www.clinicalcorrelations.org/2012/02/01/when-is-hemoglobina1c-inaccurate-in-assessing-glycemic-control/[cited on 19.3.19]

23. Michael S. Radin, Pitfalls in Hemoglobin A1c Measurement: When Results may be Misleading. J Gen Intern Med 2013; 29(2):388-94. DOI: 10.1007/s11606-013-2595-X 